\title{
Multiplex PCR identification of eight clinically relevant Candida species isolated from groin Fungal Infections among Egyptian patients
}

\author{
Marwa S. Fathi ${ }^{1}$, Nadia M. El-Sheshtawy ${ }^{1}$, Sahar S. Youssef $^{2}$, Ahmed Ghareeb $^{3}$ \\ Departments of Medical Microbiology \& Immunology ${ }^{1}$ \&Dermatology\& Venerology Diseases ${ }^{2}$, Faculty of \\ Medicine, Ain Shams University,Medical genetics center, Faculty of Medicine, Ain Shams Universitty ${ }^{3}$
}

\begin{abstract}
The prevalence of fungal infections has raised in recent years due to an increasing population of immunosuppressed patients, intensive immunosuppressive chemotherapy, increasing awareness of fungal infections, and the widespread use of broad-spectrum antibiotics. Therefore, in the last few years, the development of novel diagnostic methods has been regarded a critical issue. A multiplex PCR strategy allowed the identification of 8 clinically relevant yeasts of the Candida genus, namely C. albicans, C. glabrata, C. parapsilosis, C. tropicalis, C. krusei, C. guilliermondii, C. lusitaniae and C. dubliniensis. This method is relied on the amplification of two fragments from the ITS1 and ITS2 regions by the combination of 2 yeast-specific and 8 species specific primers in a single PCR reaction. This novel method provides a clinical diagnostic procedure with direct applicability. In addition to, it allows specific differentiation of individual Candida species within polyfungal samples.
\end{abstract}

Keywords: Candida, candidemia, diagnostic, identification, PCR, multiplex.

\section{Introduction}

Within the last two decades, the opportunistic fungus Candida albicans was the pith of cogent medical interest since it still engenders substantial morbidity with significant mortality rates especially in immunosuppressed patients as HIV positive persons, cancer patients and transplant recipients among others [1,2].Candidiasis infection vary from superficial mucosal local lesions to a disseminative disease[3].The polymorph C.albicans fungus grows either in a yeast phase or as filamentous phase (hyphae). These two types of morphology could be present in infected tissues, thus it's possibly overt that both types contribute to the pathogenesis of the microorganism[4,5].Candidaspp are the most common causative agent in fungal contagions[6],representing a range of invasive life- threatening to non-life-threatening mucocutaneous diseases. Candida albicans among Candidaspp is the most frequently common pathogenic infectious agent. It is a commensal dimorphic yeast that colonizes the skin, reproductive and gastrointestinal tract.Non C.albicans species are emergent fungal pathogens that as well colonizing human mucocutaneous surfaces[7].Mucocutaneous candidiasis is categorized into non genital disease and genitourinary disease, oropharyngeal manifestation usually common in non-genitourinary, frequently diagnosed in HIV patients[8].Whereas, genitourinary candidiasis include vulvovaginal candidiasis in females, balanitis and balanoposthitis in males and candiduria in both sexes[9].Although C.albicans is the most frequent and clinically related genus of the species, however there has been a substantial tendency towards the egression of species other than C.albicans with a particular step up in C.glabrata frequency[10].But a lesser tendency of C.parasilosis and C.tropicalis[11].The previously mentioned non C.albicans species are resistant to common therapeutic antifungal chemicals, where exact identification tests are crucial for formation and establishment of consequential antifungal therapy[11].The standard normal criterional tests for candidiasis diagnosis include culture and histopathology techniques that both lack accuracy of detection . Culture identification is relied on the visual changes that may occur in either microscopic, macroscopic morphology or pigmentation. Atypical growth may frequently take place causing confusion during the identification process, also false negative culture is possible to be noticed[11]. These methods have circumscribed specificity and low sensitivity[12].As in case of blood culture that is positive for fewer than $50 \%$ of patients with hepatosplenic candidiasis[13],are seldomly positive in patients suffering invasive aspergillosis[14]. Moreover, these procedures for identification purpose are time consuming and may cause inconclusive results, as VITEK and ID32C systems that necessitate many days before the biochemical reactions can by analyzed or interpreted[19].Therefore an alternative rapid and highly specific diagnostic procedure has been a tempting inspiration [17].Recent several molecular and immunological attempts for highly specific fungal pathogen identification include sensing and detecting the antigen, antibody or DNA.Antibody detection in bone marrow transplant(BMT) patients still remains of limited clinical diagnostic value due to the uncertain and unpredictable humoral responses[15].However molecular identification approach especially multiplex PCR and realtime PCR assay for fungal nucleic acids detection 
showed accurate and specific fungal identification plus many laboratory advantages[18].It can be applied to a variety of specimens, embracing and encompassing multiple fungal genera in one reaction showing higher specificity than common culture based methods[18]. However, in spite of its high sensitivity, it demands specific and expensive equipments This molecular reaction can detect candidemia with elevated sensitivity based on fungal ribosomal genes as DNA targets in PCR reactions[20].Buchman et al were the first to certify and demonstrate the specific Candida albicans detection possibility by PCR amplification of the lanosterolalpha demethylase (L1A1)gene[20].At the molecular identification species level for medically important yeasts identification, the highly variable sequences of internal transcribed spacer regions (ITS1) and (ITS2) that both are flanked by the relatively conserved coding regions of $28 \mathrm{~S}, 5.8 \mathrm{~S}$ and $18 \mathrm{~S}$ nuclear ribosomal (rRNA)genes were utilized in different PCR formatting [21].For ITS1 and ITS2 in vitro amplification by m-PCR technique Integrating 8 Candida species specific primers and two yeast specific primers in one single PCR reaction is performed[21].

This study represents a comparison of identification between common phenotypic culture methodsandsimple rapid multiplex PCR reaction foreight clinically relevant yeasts of the Candida genus namely C. albicans, C. glabrata, C. parapsilosis, C. tropicalis, C. krusei, C. guilliermondii, C. lusitaniae and $C$. dubliniensis.Giving rise to amplicons with different sizes with a detection limit $2.15 \pm .25$ cells $/ \mathrm{ml}$ with advantage of incorporating whole yeast cells in one single reaction.

\section{Aim of the work:}

To determine the range of candida species detected by PCR technique applied on patient specimens and to compare this technique with conventional culturetechnique which detects the phenotypic criteria of candida on culture media.

\section{Materials \&Methods}

Twenty patients with intertrigo were randomly selected from the out-patient clinic of Dermatology, Andrology and Venereology Department in Ain Shams University Hospital. An informed consent to participate was obtained from all patients. For all patients, the following was done: 1) A detailed history including age, sex, underlying disease and prior antifungal treatment. 2) Thorough general and local clinical examinations were done to all cases to search for any associated conditions .3) Swab collection. 4) Staining with Gram stain and for direct film examination. 5) Inoculation in Sabouraud's dextrose agar (SDA) and Brilliance candida agar (chromogenic media) for $48-72 \mathrm{~h}$ at room temperature .6) Identification of isolates: the yeast like colonies were identified by classical methods, while differential medium chromogenic media was used to identify candida species by colony morphology and pigmentation according to the by chromogenic identification methods [22]. 6) Strains were isolated and stored in glycerol for PCR identification.

\section{Primer design}

Two Yeast specific universal primers UNI1(5`-GTCAAAC TTGGTCATTTA-3`) and UNI2 (5`TTCTTTTCCTC CGCTTATTGA-3`) were incorporated to in vitro amplify the internal transcribed spacer regions 1 (ITS1) and 2 (ITS2), integrating the 5.8S rRNA of the most common yeast pathogens[23]. In addition, the species-specific primers Calb, Cgla, Ckru, Cpar, Ctro, Clus, Cgui and Cdubwere designed based on the sequence data for the ITS1 and ITS2 regions of the reference strains and of all clinical isolates from the Candida genus available in the EMBL/GenBank databases. The sequences were compared using the DNAMAN for Windows software (Lynnon Corporation, Quebec, Canada) in order to design primers to specifically amplify DNA from ( C. albicans, C. glabrata, C. krusei, C. parapsilosis, C. tropicalis, C. lusitaniae, C. guilliermondii and C. dubliniensis) respectively (Table 1).

\section{DNA Isolation}

For DNA extraction, cells were grown overnight in YEPD medium at $26^{\circ} \mathrm{C}$ on a mechanical aerated shaker (150 rpm) [24].Centrifugation of cells for harvesting at 3,000 for $5 \mathrm{~min}$ [24]then the pellet suspended in $200 \mathrm{ml}$ of lysis buffer (2\% Triton X-100, 1\% SDS, $100 \mathrm{mMNaCl}, 10 \mathrm{mMTris}-\mathrm{HCl}$, and $1 \mathrm{mM}$ EDTA, pH 8.0). Disruption of cells by $200 \mathrm{ml}$ of $0.5 \mathrm{~mm}$ diameter glass beads and $200 \mathrm{ml}$ of chloroform/phenol (1:1) were added and the tubes were shaken for three 60-second intervals with periods of cooling on ice[24]. Cell remains were eliminated centrifugation at $3,000 \mathrm{~g}$ for 5 minutes,the supernatant was collected and $1 \mathrm{ml}$ of cold isopropanol was added prior to mixing by inversion. Then Centrifugation of tubes at 3,000 g for 3 minutes where the sediment was suspended in $400 \mathrm{ml}$ of TE buffer (100 mMTris-HCl, $1 \mathrm{mM}$ EDTA, pH 8.0)[25]. A 5min treatment with RNase A $(1 \mathrm{mg} / \mathrm{ml})$ at $37^{\circ} \mathrm{C}$ was then carried out before adding $10 \mathrm{ml}$ of $3 \mathrm{M}$ sodium acetate. For further DNA precipitation, $1 \mathrm{ml}$ of isopropanol was added, then mixing by inversion for centrifugation. Finally, the sediment was air-dried and the DNA suspended in $50 \mathrm{ml}$ of ultrafiltered water. DNA content and 
purity were determined by spectral photometry at 260 and $280 \mathrm{~nm}$ and diluted to a $100 \mathrm{ng} / \mathrm{ml}$ final concentration[25].

Table 1 Universal and species-specific primers used in Candida species amplification and size of fragments visualized under agarose gel electrophoresis

\begin{tabular}{|c|c|c|c|}
\hline Species & Primer name & Sequence $\left(5^{\prime}-3^{\prime}\right)$ & Amplicon size (bp)* \\
\hline $\begin{array}{l}\text { Clinically relevant } \\
\text { yeasts }\end{array}$ & $\begin{array}{l}\text { UNI1 } \\
\text { UNI2 }\end{array}$ & $\begin{array}{l}\text { GTCAAACTTGGTCATTTA } \\
\text { TTCTTTTCCTCCGCTTATTG }\end{array}$ & Trost et al., 2004 [22] \\
\hline C. albicans & Calb & AGCTGCCGCCAGAGGTCTAA & $583 / 446$ \\
\hline C. glabrata & Cgla & TTGTCTGAGCTCGGAGAGAG & $929 / 839$ \\
\hline C. krusei & Ckru & CTGGCCGAGCGAACTAGACT & $590 / 169$ \\
\hline C. tropicalis & Ctro & GATTTGCTTAATTGCCCCAC & $583 / 507$ \\
\hline C. parapsilosis & Cpar & GTCAACCGATTATTTAATAG & $570 / 370$ \\
\hline C. guilliermondii & Cgui & TTGGCCTAGAGATAGGTTGG & $668 / 512$ \\
\hline C. lusitaniae & Clus & TTCGGAGCAACGCCTAACCG & $433 / 329$ \\
\hline C. dubliniensis & Cdub & CTCAAACCCCTAGGGTTTGG & $591 / 217$ \\
\hline
\end{tabular}

In QIAamp mini spin columns with $2 \mathrm{ml}$ collection tubes, centrifugation at 5,000 $\mathrm{g}$ for $1 \mathrm{~min}$ then washing twice with $500 \mathrm{ml}$ of AW buffer. The columns were then washed twice with $50 \mathrm{mM}$ EDTA and twice with AW buffer in order to chelate PCR inhibitory factors. DNA was eluted with $100 \mathrm{ml}$ of previously heated AL buffer and kept at $-20^{\circ} \mathrm{C}$ until PCR. ATL lysis buffer, AL buffer, AW buffer, proteinase $\mathrm{K}$ and the spin columns were purchased from Qiagen, Hilden, Germany.

\section{PCR Amplification}

Multiplex PCR amplification reaction was carried out in a $20 \mathrm{ml}$ volume consisting of 0.8_PCR buffer [160 mM (NH4)2SO4, 670 mMTris-HCl (pH 8.8)], $3.5 \mathrm{mM} \mathrm{MgCl2,} \mathrm{dNTP} \mathrm{mixture} \mathrm{(200} \mathrm{mM} \mathrm{each),} \mathrm{primer}$ mixture (UNI1 and UNI2, $0.55 \mathrm{mM}$ each; Cgui, $0.05 \mathrm{mM}$; Calb and Ckru, $0.15 \mathrm{mM}$ each; Cgla, Ctro and Clus, $0.2 \mathrm{mM}$ each; Cpar, $0.3 \mathrm{mM}$; Cdub, $0.4 \mathrm{mM}$ ), $1 \mathrm{U}$ TaqDNApolymerase and $50 \mathrm{ng}$ genomic DNA template, with the remaining volume consisting of sterilized water[21]. The DNA template amout used quantified by spectrophotometry[20]. For colony-PCR, part of a single colonywas suspended directly in the PCR mixture with a sterile toothpick. PCR was routinely performed in a BiometraTpersonal (WhatmanBiometra, Goettingen, Germany) thermal cycler under the following cycling conditions: 40 cycles of $15 \mathrm{~s}$ at $94^{\circ} \mathrm{C}, 30 \mathrm{~s}$ at $55^{\circ} \mathrm{C}$, and 45 $\mathrm{s}$ at $65^{\circ} \mathrm{C}$, after a 10 -min initial period of DNA denaturation and enzyme activation at $94{ }^{\circ} \mathrm{C}[21]$. Additionally, multiplex PCR reactions were performed in four different thermal cyclers: iCycler and MyCycler (Bio- Rad, CA, USA), Primus 96 (MWG Biotech AG, Ebersberg, Germany) and GeneAmp PCR System9600 (PerkinElmer, MA, USA) in order to confirm PCR reaction reproducibility. Negative control reactions were carried out simultaneously with each test run by substituting the template DNA with sterilized water inthe PCR mixture[27]. $10 \mathrm{ml}$ aliquots of each amplification product were separated by electrophoresis in a $2 \%$ agarose gel. Ethidium bromide staining $(0.5 \mathrm{mg} / \mathrm{ml})$ allowed the visualization of DNA fragments witha digital imaging system (Alpha Innotech Corporation, CA, USA) and species identification was possible by comparison with a 100-bp DNA ladder (Fermentas International Inc., Ontario, Canada).

Statistical analysis: statistical presentation and analysis of the present study was conducted using the mean standard error, unpaired bivarientt.test and chi-square using SPSS program version:22.0.0.0.

\section{Results}

A total number of 20 patients were enrolled in thisstudy. The patients were 12 male (60) and 8 females (40). With mean age 31 range (0.65-39).

Results of culture on chromogenic media showed 11 positive samples for candida growth on chromogenic media, 2 samples were (c.alb+c.kreusi) (10\%) indicated by green and pink -brown color change on chromogenic media respectively(figures 2,5), 1 (c.alb + c. parapsilosis) $(5 \%)$ indicated by green and brown color change respectively(figures2,6), 1 (c.alb + c.tropicalis) $(5 \%)$ indicated by green and dark blue color change(figure 3$), 1$ (c.alb + c.glabrata) (5\%) indicated by green and yellow(figure3), 2 (c.kreusi) (10\%)(figure 5), 1 (c.parapsilosis) (5\%)(figure 6), 1(c.tropicalis) (5\%)(figure 4) and 2 (c.glabrata) (10\%)(figure 3). The rest of samples (9) were negative(45\%)as they showed no color change on chromogenic media . 


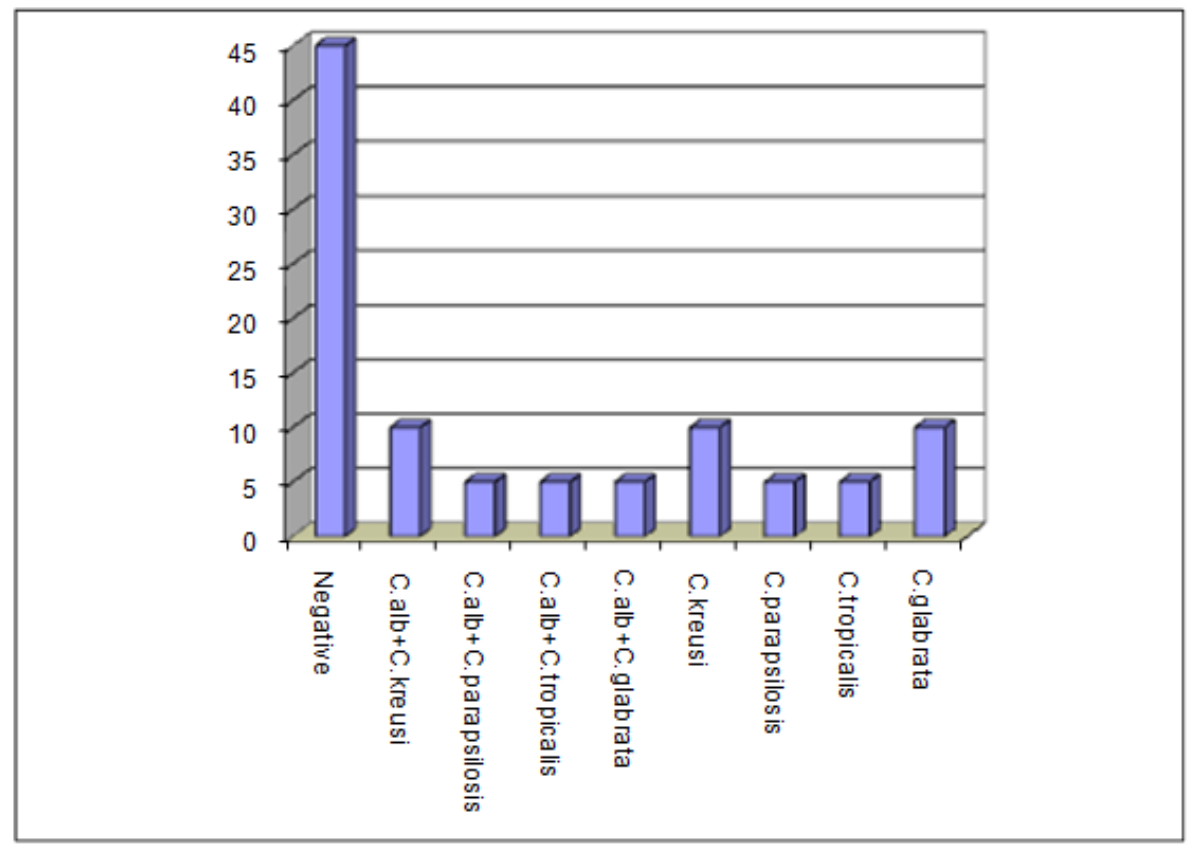

Fig. (1): Results of culture on chromogenic media.

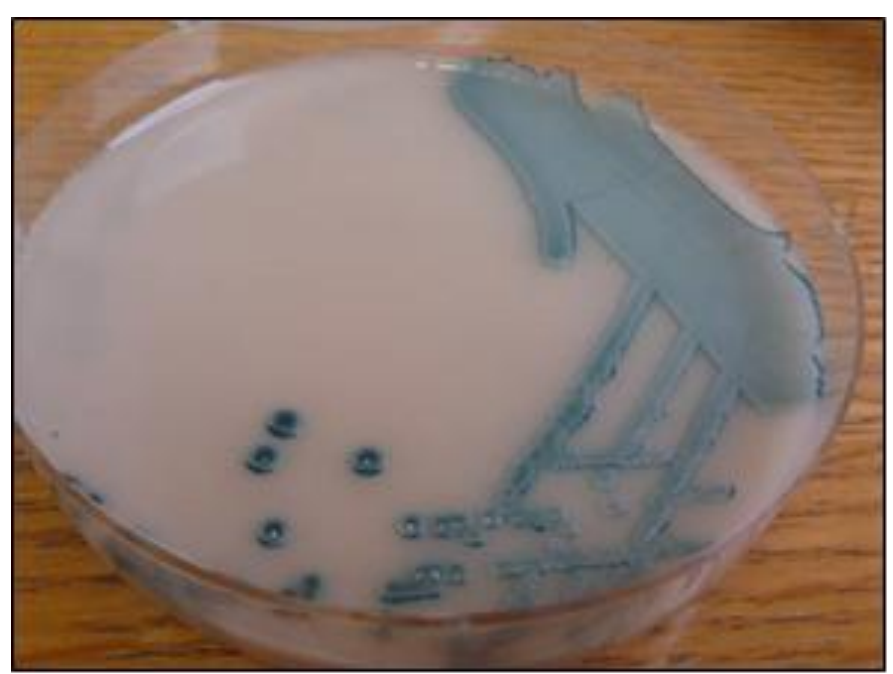

Fig. (2): Growth of Candida Albicans (green) on brilliance agar

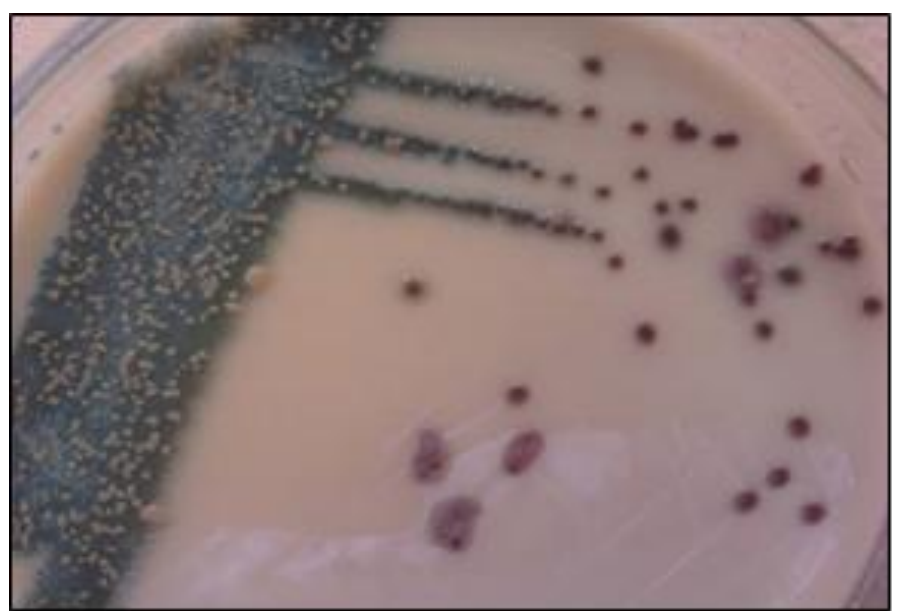

Fig. (3): Growth of Candida Tropicalis( dark blue) with glabrata (light brown) and Albicans (green) on brilliance agar. 


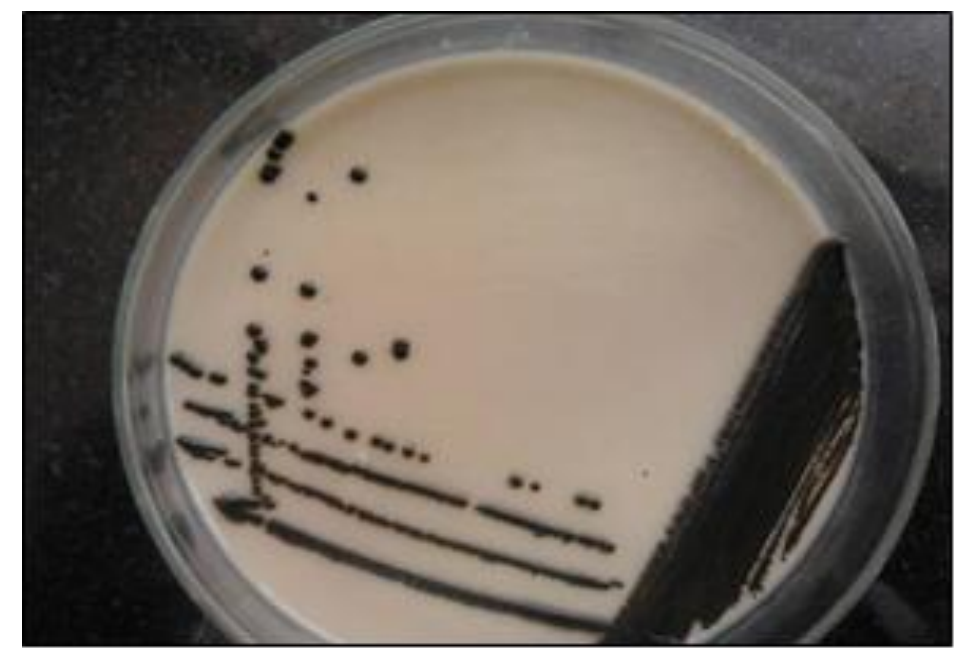

Fig. (4): Growth of Candida Tropicalis( dark blue) on brilliance agar

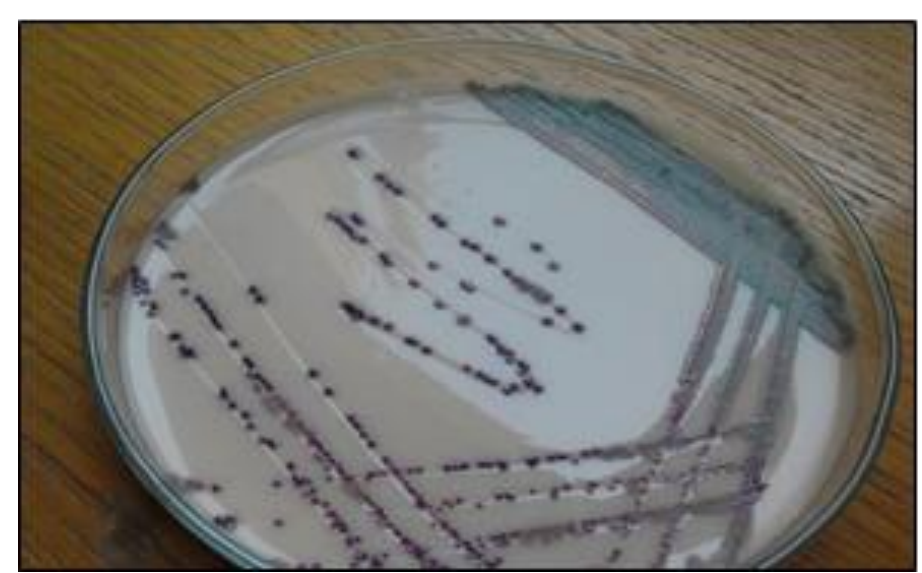

Fig. (5): Growth of Candida Krusei (pink)on brilliance agar.

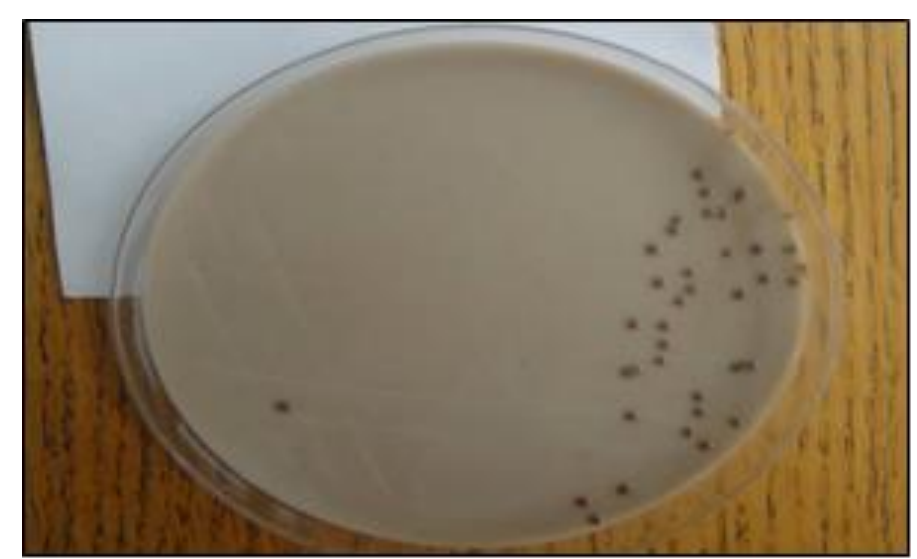

Fig. (6): Growth of Candida Parapsilosis(brown) on brilliance agar.

Results of PCR with incidence of each candida were candida albicans 7(38.9\%), candida kreusi 4(22.2\%), candida parapsilosis $2(11.1 \%)$, candida tropicalis $1(5.6 \%)$ and candid glabrata $4(22.2 \%)$

Table(2): Results of PCRwithincidenceof eachcandida species

\begin{tabular}{|l|l|l|}
\hline ResultsonPCR & Frequency & Percent \\
\hline C.albican & 7 & 38.9 \\
\hline C.kreusi & 4 & 22.2 \\
\hline C.parapsilosis & 2 & 11.1 \\
\hline C.tropicalis & 1 & 5.6 \\
\hline C.glabrata & 4 & 22.2 \\
\hline Total & 18 & 100.0 \\
\hline
\end{tabular}




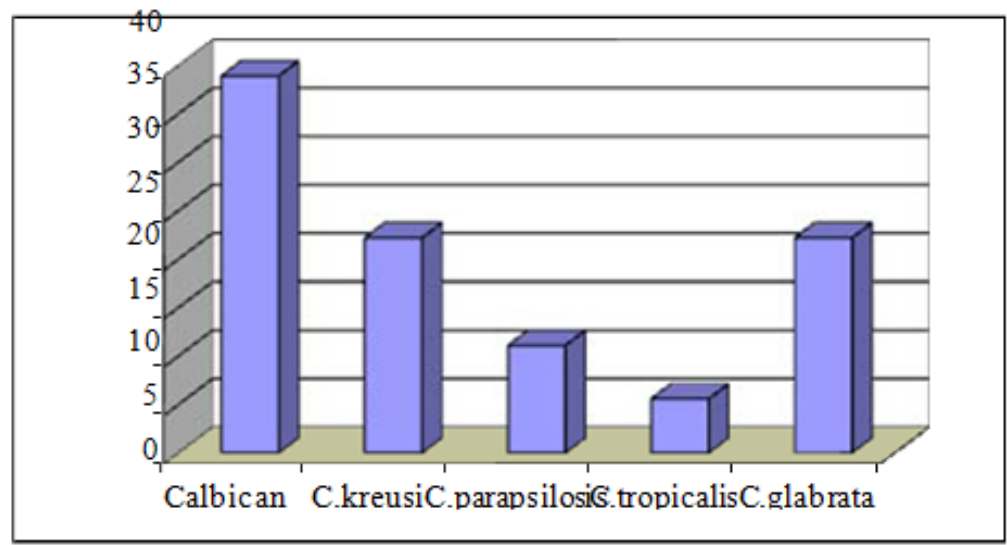

Fig.(7): Results of PCR withincidenceof eachcandidaspecies
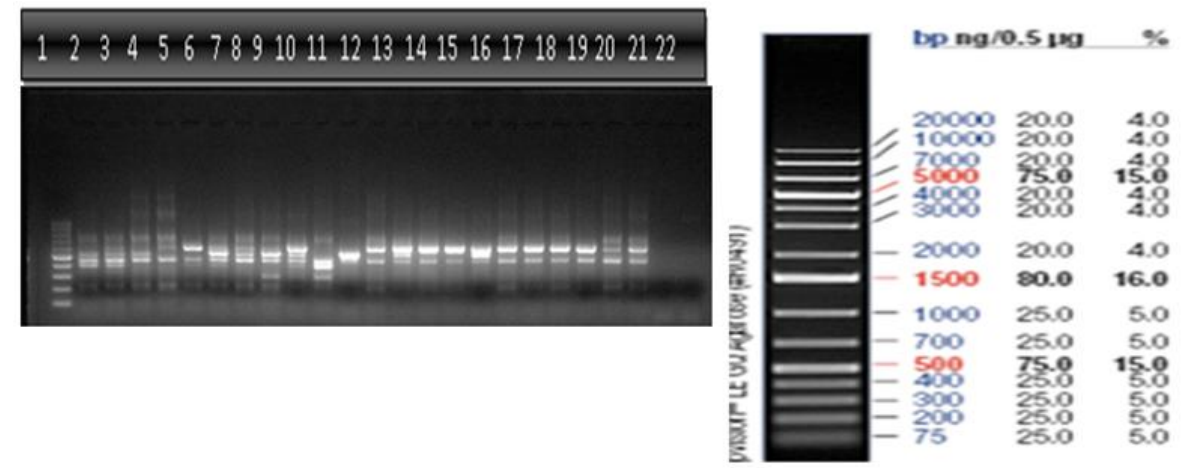

Fig. (8): Gel electrophoresis showing PCR products fragment size measured against GeneRuler ${ }^{\mathrm{TM}} 100 \mathrm{bp}$ Plus DNA Ladder. According to fragment size Candida spp. Were identified as follows: Lane 1: C. lusitanae, Lane 2,3,4: C. glabrata, Lane 5-9, 11,12: C.guillermondi, Lane 10: C.krusei, Lane: 13-20:C.albicans, Lane 21: C.tropicalis, Lane 22: C.parapsilosis

Table(3):Comparison betweentheresultsobtainedby chromogenicmediaandPCRasregardidentificationof candida

\begin{tabular}{|c|c|c|c|c|c|c|}
\hline \multicolumn{7}{|c|}{ species } \\
\hline & \multicolumn{2}{|c|}{ ResultsbyChromogenic agar } & \multicolumn{2}{|c|}{ ResultsbyPCR } & \multicolumn{2}{|c|}{ Chi-squaretest } \\
\hline & No. & $\%$ & No. & $\%$ & $x^{2}$ & $\begin{array}{l}\text { P-value } \\
\end{array}$ \\
\hline Calbican & 5 & $31.25 \%$ & 7 & $38.89 \%$ & \multirow{5}{*}{0.694} & \multirow{5}{*}{0.952} \\
\hline C.kreusi & 4 & $25.00 \%$ & 4 & $22.22 \%$ & & \\
\hline C.parapsilosis & 2 & $12.50 \%$ & 2 & $11.11 \%$ & & \\
\hline C.tropicalis & 2 & $12.50 \%$ & 4 & $5.56 \%$ & & \\
\hline C.glabrata & 3 & $18.75 \%$ & 18 & $22.22 \%$ & & \\
\hline Total & 16 & 100.0 & & 100.0 & & \\
\hline
\end{tabular}

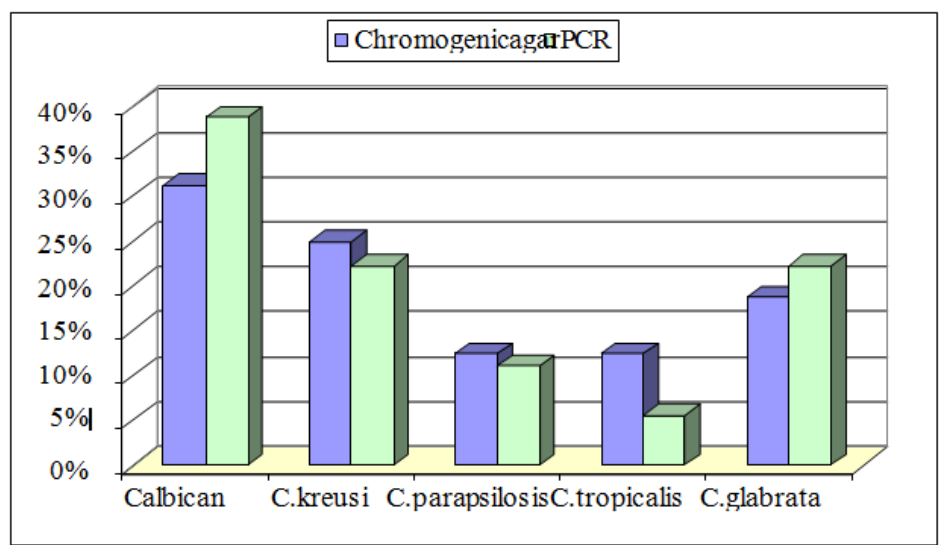

Fig.(9): Comparisonbetweentheresultsobtainedby chromogenic mediaandPCR as regardidentificationof candidaspecies. 
No significant statistical difference was found between the results of chromogenic and PCR as regard identification of candida species $(\mathrm{P}>0.05)$ and showed good correspondence with chromogenic media (concordance value $79.1 \%$ ). Both have nearby ability to discriminate Candida species

Table(4):ConcordanceratebetweenPCRandchromomeric agar

\begin{tabular}{|l|l|l|l|l|}
\hline \multirow{2}{*}{} & \multicolumn{2}{|l|}{ ResultsbyPCR } & \multicolumn{2}{l|}{ ResultsbyChromogenic agar } \\
\cline { 2 - 5 } & No. & \% & No. & \% \\
\hline Calbican & 7 & $38.89 \%$ & 5 & $31.25 \%$ \\
\hline C.kreusi & 4 & $22.22 \%$ & 4 & $25.00 \%$ \\
\hline C.parapsilosis & 2 & $11.11 \%$ & 2 & $12.50 \%$ \\
\hline C.tropicalis & 1 & $5.56 \%$ & 2 & $12.50 \%$ \\
\hline C.glabrata & 4 & $22.22 \%$ & 3 & $18.75 \%$ \\
\hline Concordancevalue & $79.1 \%$ & \multicolumn{3}{|l}{} \\
\hline Discrepancy value & $20.9 \%$ \\
\hline
\end{tabular}

Table(5):Sensitivityandspecificityforchromogenicagarin comparisonwithPCRresults

\begin{tabular}{|l|l|l|l|l|l|l|}
\hline & & C.albican & C.Kreusi & Parapsilosis & C.tropicalis & C.glabrata \\
\hline Chromogenicagar & Sensitivity & 71.4 & 100.0 & 100.0 & 100.0 & 75.0 \\
\hline M-PCR & Specificity & 100.0 & 100.0 & 100.0 & 94.4 & 100.0 \\
\hline
\end{tabular}

\section{Discussion}

The cornerstone of this study is a comparison between standard phenotypic methodology and multiplex PCR assay for specific identification and sensitive detection of eight relevant Candida species namely $C$. albicans, C. glabrata, C. parapsilosis, C. tropicalis, C. krusei, C. guilliermondii, C. lusitaniae and C. dubliniensisin polyfungal samples for accurate clinical diagnostic and therapeuticpurposes. Phenotypicculture techniques for morphological identification relied on the visual alterations of the micro and macroscopic features of the polymorph fungus as well as pigmentation.Multiplex PCR method based on in vitro amplification of the fungal ribosomal genes for molecular identification purpose. The second approach is carried out in a single multiplex PCR reaction coexisting 8 clinically relevant Candida species isolated from 20 swab samples randomly collected from out patient clinic of dermatology and venereology Department, in Ain Shams University Hospitals. The patients were not receiving any topical or systemic treatment for their conditions, and the present work was approved by ethical committee. They all were subjected to history taking, clinical examination, specimen collection (lesional swab), gram staining and culture for all collected samples on sabouraud dextrose agar and selective chromogenic media (brilliance candida agar). Then all the positive culture media on chromogenic media was subjected to PCR reactions.The patients were 12 male (60) and 8 females (40) With mean age 31 range (0.65-39).

The suggested $\mathrm{m}$-PCR reaction based on the combined usage of universal primers UNI1 and UNI2 and 8 Candida species-specific primers to in vitro amplify the internal transcribed space regions ITS1 and ITS2 (tab.1), including the 5.8S rRNA region[21].Taking advantage of the high copy number of r-RNA genes, different lengths of ITS regions and the high variability of these regions among Candida species.Phenotypic Results obtained from differential chromogenic media after 28 days showed characteristic pigmentations(fig.2,6).On the other handm-PCR products obtained and identified within as little as 5 hours(tab.2), reveled the characteristic band pattern(fig.8),discriminating the different species present in polyfungal samples( fig.7).Comparison between both results as regard identification of Candida species(fig.9), showed no significant statistical differences where ( $\mathrm{P}>0.05)$ (tab.3).The concordance rate between PCR and chromogenic agar was (79.1\%),however many discrepancies was also recorded in such comparison(20.9\%) (tab.4).Also sensitivity and specificity from chromogenic agar in comparison with PCR products showed nearby ability to discriminate Candida species(Tab.5).

In this study 20 swab samples yielded poor candida species outcome, especially C.Tropicalis that was one sample identified by m-PCR and two identified by chromogenic agar representing $(5.56 \%, 12.50 \%)$ respectively(fig.1)\&(tab.2). So for further investigations, it's highly recommended to use cultural isolates rather than swab samples for increased fungal specimens for better confirmation and deep understanding. Although both techniques showed nearby discrimination of Candida species,however m-PCR reaction is highly specific and moresensitive, but it still an expensive equipment not readily accessible to diagnostic laboratories in contrast to common culture methods. M-PCR molecular technique has plenty of laboratory advantages rather than phenotypic methodology as we noticed. It's time saving, few hours for the results to come up, in contrast to standard morphological, cultural and biochemical features that takes 28 days. Highly specific with sensitive detection limit $2.15 \pm .25$ cells $/ \mathrm{ml}$ advantaging the occurrence possibility offalse negative culture results. Moreover,wholeminor yeast cells could be directly incorporated in the reaction, easily implemented, cost effective since no need for either the restriction enzymes or DNA probes[23]. In addition, it can be appliedto a 
variety of specimen types testing several clinical samples for rapid identification and consequently provides accurate therapeutic clue.

Conclusion:Both PCR and chromogenic agar media showed good correspondence in Candida species identification (concordance value 79.1\%). Also multiplex PCR was rapid and effective in the identification of Candida species allowing the detection of more than one species at the same time.

\section{References}

[1]. Vincent, J. L., Anaissie, E., Bruining, H., Demajo, W., el Ebiary, M., Haber, J., Hiramatsu, Y., Nitenberg, G., Nystrom, P. O., Pittet, D., Rogers, T., Sandven, P., Sganga, G., Schaller, M. D., and Solomkin, J. (1998) Epidemiology, diagnosis and treatment of systemic Candida infection in surgical patients under intensive care. Intensive Care Med. 24, 206-216.

[2]. Sandven, P. (2000) Epidemiology of candidemia. Rev. Iberoam. Micol.17, 73-81.

[3]. Garber, G. (2001) An overview of fungal infections. Drugs 61, Suppl. 1, 1-12.

[4]. Gow, N. A. (1997) Germ tube growth of Candida albicans. Curr.Top. Med. Mycol. 8, 43-55.

[5]. Mitchell, A. P. (1998) Dimorphism and virulence in Candida albicans. Curr.Opin. Microbiol. 1, 687-692.

[6]. Richards, M. J., J. R. Edwards, D. H. Culver, and R. P. Gaynes. (2000) Nosocomial infections in combined medical-surgical intensive care units in the United States.Infect. Control Hosp. Epidemiol. 21:510-515.

[7]. Sobel, J. D. (2006) The emergence of non-albicans Candida species as causes of invasive candidiasis and candidemia. Curr. Infect. Dis. Rep. 8:427-433.

[8]. De Repentigny, L., D. Lewandowski, and P. Jolicoeur. (2004)Immunopathogenesis of oropharyngeal candidiasis in human immunodeficiency virus infection. Clin.Microbiol.Rev. 17:729-759.

[9]. Sobel, J. D., S. Faro, R. W. Force, B. Foxman, W. J. Ledger, P. R. Nyirjesy, B. D. Reed, and P. R. Summers. (1998) Vulvovaginal candidiasis: epidemiologic, diagnostic, and therapeutic considerations. Am. J. Obstet. Gynecol. 178:203-211.

[10]. Tortorano, A. M., Peman J., Bernhardt H., et al.(2004) Epidemiology of candidaemia in Europe: results of 28-month European Confederation of Medical Mycology (ECMM) hospital-based surveillance study. Eur J ClinMicrobiol Infect Dis 23: 317-322.

[11]. Kao A.S., Brandt M.E., Pruitt W.R., et al.(1999) The epidemiology of candidemia in two United States cities: results of a populationbased active surveillance. Clin Infect Dis 29: 1164-1170.

[12]. Duthie, R., and D. W. Denning. (1995). Aspergillusfungemia: report of two cases and review. Clin. Infect. Dis. 20:598-605.

[13]. Thaler, M., B. Pastakia, T. H. Shawker, T. O'Leary, and P. A. Pizzo. (1988) Hepatic candidiasis in cancer patients: the evolving picture of the syndrome. Ann. Intern. Med. 108:88-100.

[14]. Wald, A., W. Leisenring, J. van Burik, and R. A. Bowden. (1997). Natural history of Aspergillus infections in a large cohort of patients undergoing bone marrow transplantation. J. Infect. Dis. 175:1459-1466.

[15]. Hurst, S. F., D. W. McLaughlin, G. Reyes, E. Reiss, and C. J. Morrison. (1994) Development of an inhibition EIA to detect galactomannanemia/uria: comparison to the pastorexAspergillus latex agglutination test (PALA) for the diagnosis of invasive aspergillosis, abstr. D43, p. 154. In Program and abstracts of the 34th Interscience Conference on Antimicrobial Agents and Chemotherapy.American Society for Microbiology, Washington, D.C.Markham A.(1993) The polymerase chain reaction: a tool for molecular medicine. BMJ306(6875):441-446.

[16]. Hay RJ and Jones RM (2010): New molecular tools in the diagnosis of superficial fungal infections. Clinics in Dermatology; 28:190-196.

[17]. Kasai M, Francesconi A, Petraitiene R, Petraitis V, Kelaher AM, Kim HS, Meletiadis J, Sein T, Bacher J, Walsh TJ.(2006) Use of quantitative real-time PCR to study the kinetics of extracellular DNA released from Candida albicans, with implications for diagnosis of invasive candidiasis. J Clin Microbiol;44(1):143- 150.

[18]. Ali A. F., Parivash K., Farideh Z., etal. (2013) Candida Species in Cutaneous Candidiasis Patients in the Guilan Province in Iran; Identified by PCR-RFLP Method ActaMedicaIranica, 51(11): 799-804.

[19]. Fenn J.P., Segal H., Barland B., et al.(1994) Comparison of updated Vitek Yeast Biochemical Card and API 20C yeast identification systems. J ClinMicrobiol 32: 1184-1187.

[20]. Buchman T.G., Rossier M., Merz W.G., Charache P.(1990) Detection of surgical pathogens by in vitro DNA amplification. Part I. Rapid identification of Candida albicans by in vitro amplification of a fungus-specific gene.Surgery 108: 338-346.

[21]. A. Carvalho, S. Costa-de-Oliviera, M. L. Martins, C. Pina-Vaz, A. G. Rodriguess, P. Ludovico , F. Rodriguess (2007) Multiplex PCR identification of eight clinically relevant Candida species Med. Mycology, 45, 619-627.

[22]. Milne L. (1996): Fungi in Mackie and McCarteny practical medical microbiology .14 $4^{\text {th }}$ ed.p:695.

[23]. Trost A, Graf B, Eucker J, et al.(2000) Identification of clinically relevant yeasts by PCR/RFLP. J Microbiol Methods; 56: 201_211.

[24]. Xu J, Ramos AR, Vilgalys R, Mitchell TG (2000). Clonal and spontaneous origins of fluconazole resistance in Candida albicans. J ClinMicrobiol; 38: 1214-1220.

[25]. Hay RJ and Jones RM (2010): New molecular tools in the diagnosis of superficial fungal infections. Clinics in Dermatology; 28:190-196.

[26]. Catherine Coignard, Steven F. Hurst, Lynette E. Benjamin, Mary E. Brandt, David W. Warnock, and Christine J. Morrison (2004): Resolution of Discrepant Results for Candida Species Identification by Using DNA Probes. Journal of Clinical Microbiology, p. 858-861.

[27]. Liguori G, Gallé F, Lucariello A, Di Onofrio V, Albano L, Mazzarella G, D’Amora M, Rossano F (2010): Comparison between multiplex PCR and pheno-typic systems for candida spp. Identification. New Mirobiologica; 33:63-67. 